\section{CINE Y SOCIEDAD: LA CONSTRUCCIÓN DE LOS PERSONAJES MASCULINOS $Y$ FEMENINOS EN EL 'LANDISMO' TARDOFRANQUISTA}

\author{
Miguel Ángel Huerta Floriano \\ Universidad Pontificia de Salamanca \\ mahuertafl@upsa.es \\ Ernesto Pérez Morán \\ Universidad de Medellín \\ eperezm@udem.edu.co
}

Cómo citar este artículo/Citation: Huerta Floriano, M. A.; Pérez Morán, E. (2015). "Cine y sociedad: la construcción de los personajes masculinos y femeninos en el 'landismo' tardofranquista". Arbor, 191 (773): a243. doi: http://dx.doi. org/10.3989/arbor.2015.773n3013

Recibido: 4 junio 2014. Aceptado: 23 junio 2014.

RESUMEN: Este trabajo parte de las relaciones existentes entre la teoría del cine y su dimensión sociológica para formular un análisis sobre el 'landismo', uno de los fenómenos con implicaciones sociales más relevantes en la historia del cine español. En concreto, se sintetizan las principales estrategias narrativas empleadas en un corpus de 19 largometrajes que construyen una imagen recurrente de la masculinidad y la feminidad a través de los personajes principales. Del estudio se concluye un rol contrapuesto de hombres y mujeres en las relaciones de pareja, lo cual no impide la consecución de la estabilidad afectiva y familiar

PALABRAS CLAVE: Cine; sociedad; 'landismo'; personajes; género.

\section{CINEMA AND SOCIETY: THE CONSTRUCTION OF MALE AND FEMALE CHARACTERS IN LATE FRANCOISM 'LANDISMO'}

Copyright: (C) 2015 CSIC. Este es un artículo de acceso abierto distribuido bajo los términos de la licencia Creative Commons Attribution-Non Commercial (by-nc) Spain 3.0.

ABSTRACT: This work is based on the relationship between film theory and its sociological dimension, to formulate an analysis of 'landismo', one of the most important social phenomena in the history of Spanish cinema. Specifically, this study synthesises the main narrative strategies employed in a corpus of 19 films that build a recurring image of masculinity and femininity through the main characters. The study concludes an opposed role between men and women inside relationships, which does not prevent the achievement of personal and family stability.

KEYWORDS: Cinema; Society; 'Landismo'; Characters; Gender. 


\section{INTRODUCCIÓN}

Desde que surgió a finales del siglo XIX para convertirse en uno de los medios de comunicación más influyentes en las dinámicas sociales, el cine despertó una reflexión permanente sobre su capacidad para crear, reforzar y reflejar valores presentes en los grupos humanos a los que se dirige. El hecho de que la reproducción gráfica de imágenes en movimiento propiciara discursos articulados a partir de un lenguaje con un vigor realista hasta entonces desconocido, solo fue el preludio de otros debates que siguen vivos, como, por ejemplo, el relacionado con la capacidad y los límites del cine para constituir un testimonio de la realidad (Gunning, 2007).

Era solo cuestión de tiempo que la teoría fílmica fuera, como disciplina, más allá de la pura reflexión estética y/o semiótica para interesarse también -y en un sentido amplio- por lo sociológico. Las zonas de intersección entre cine y sociología no evitaron la necesidad de superar incertidumbres para llegar a caminos que resultaran fértiles (Casetti, 2000, pp. 127129). De entre todos ellos es especialmente significativa la vertiente representacional, pues partimos de la convicción de que los discursos de ficción constituyen también una forma de proyectar las características de las sociedades que los circundan, convirtiéndose así para el futuro en documentos de indiscutible valor histórico (Rosenstone, 2006).

En cuanto a las representaciones que de la sociedad hacen los textos fílmicos destaca por pionero el estudio realizado tras la II Guerra Mundial sobre las producciones expresionistas alemanas (Kracauer, $1995)^{1}$. No obstante, los presupuestos de una teoría sociológica del cine desde la perspectiva representacional se tornarían más precisos gracias a la sendas abiertas en los años setenta por Ferro (1977) y, especialmente, por Sorlin (1977). Para este las películas no testimonian la realidad al duplicarla sino que son el resultado de decisiones creativas, expectativas del público y formas expresivas dominantes en el tiempo que las ve nacer, de tal modo que representan lo visible de una sociedad y no a esta en su conjunto. A partir de Sorlin se concluye que el cine revela los hábitos, esquemas y convenciones sociales de la percepción o, dicho de otro modo, es una fuente muy útil para indagar en la mentalidad dominante de cada coyuntura histórica.

Nuestro trabajo parte de ese caldo de cultivo teórico para delimitar el alcance de un objeto particular de estudio: el análisis del cine popular del tardofranquismo que tuvo por protagonista al actor Alfredo Lan$\mathrm{da}$, con especial énfasis en la imagen que los filmes proyectaban sobre hombres y mujeres a través de los personajes principales.

En concreto, la muestra está formada por los largometrajes de ficción que contaron con Landa como cabeza de cartel en el período 1969-1975 (Tabla 1) y que superaron el millón de espectadores en taquilla (cifra que garantiza la popularidad de cada uno por ellos separado y, desde luego, la de la suma del conjunto).

Durante la última década del franquismo coincidieron varias circunstancias que alimentan el interés apriorístico de una investigación que, partiendo de los textos cinematográficos, sintetiza la visión que dichas ficciones mantenían sobre el entorno circundante. La popularidad de cierto tipo de producciones de la época encuentra en el ciclo protagonizado por Landa uno de los supuestos más conocidos e insertos en la memoria colectiva española, cuestión repetida con insistencia en los medios de comunicación con motivo del fallecimiento del actor en mayo de 2013. Prueba de que se trataba de un caso de estrellato con connotaciones de fenómeno social fue la fama adquirida por el sustantivo 'landismo', acuñado por el crítico Tomás García de la Puerta, según explica Ordóñez (2008, p. 183).

Dado el volumen de datos recogidos, centramos los resultados en uno de los aspectos más destacados de esta sociología del 'landismo': los roles genéricos que maneja en la construcción de los personajes principales. Se trata de identificar qué estrategias creativas seguían las producciones para vehicular un discurso más o menos sistemático sobre las masculinidad y la feminidad, con especial énfasis en el orden de lo sentimental y/o lo sexual, así como en la imagen que proponen de los respectivos papeles que tienen en el seno de la institución familiar. Nos centraremos en los argumentos de aquellos filmes que forman parte de la muestra, concretamente en las motivaciones de los personajes y las resoluciones de las tramas, aspectos narrativos a los que podremos sumar algunas soluciones formales y de puesta en escena que se pongan al servicio de la creación de discurso. $Y$ todo ello lo hacemos guiados por la convicción de que los filmes populares constituyen una herramienta eficaz para lo que podría considerarse como cultivo de la imaginación sociológica (Prendergast, 1986). 
Tabla 1. Películas protagonizadas por Alfredo Landa con más de un millón de espectadores (1969-1975)

\begin{tabular}{|c|c|c|c|c|c|}
\hline Título & Año & Director & Guionista (s) & $\begin{array}{l}\text { Compañía (s) de } \\
\text { producción }\end{array}$ & $\begin{array}{l}\text { Número de } \\
\text { espectadores }\end{array}$ \\
\hline $\begin{array}{l}\text { ¿Por qué te engaña } \\
\text { tu marido? }\end{array}$ & 1969 & Manuel Summers & $\begin{array}{l}\text { F. Summers, M. Sum- } \\
\text { mers, W. Fernández } \\
\text { Flórez (novela) }\end{array}$ & $\begin{array}{l}\text { Impala/Kalender Films } \\
\text { International }\end{array}$ & 1.413 .256 \\
\hline $\begin{array}{l}\text { Cuatro noches de } \\
\text { boda }\end{array}$ & 1969 & Mariano Ozores & $\begin{array}{l}\text { Alfonso Paso } \\
\text { Mariano Ozores }\end{array}$ & Filmayer & 1.174 .480 \\
\hline El alma se serena & 1970 & $\begin{array}{l}\text { José Luis Sáenz de } \\
\text { Heredia }\end{array}$ & $\begin{array}{l}\text { J. L. Sáenz de Heredia, } \\
\text { M. Ozores, J. J. Alonso } \\
\text { Millán (obra de teatro) }\end{array}$ & $\begin{array}{l}\text { Chapalo Films/ } \\
\text { Universal Film Española }\end{array}$ & 1.325 .191 \\
\hline Cateto a babor & 1970 & Ramón Fernández & $\begin{array}{l}\text { V. Coello } \\
\text { V. Escrivá }\end{array}$ & $\begin{array}{l}\text { Aspa P. Cinematográficas/ } \\
\text { Filmayer }\end{array}$ & 1.792 .896 \\
\hline $\begin{array}{l}\text { No desearás al } \\
\text { vecino del quinto }\end{array}$ & 1970 & Ramón Fernández & $\begin{array}{l}\text { J. J. Alonso Millán, } \\
\text { Sandro Continenza }\end{array}$ & $\begin{array}{l}\text { Atlántida Films/ } \\
\text { Fida Cinematográfica }\end{array}$ & 4.371 .624 \\
\hline Los días de Cabirio & 1971 & Fernando Merino & $\begin{array}{l}\text { J. M. Lamet, } \\
\text { Alfonso Paso }\end{array}$ & José Frade P.C. & 1.660 .922 \\
\hline $\begin{array}{l}\text { No desearás la } \\
\text { mujer del vecino }\end{array}$ & 1971 & Fernando Merino & $\begin{array}{l}\text { J. J. Alonso Millán, } \\
\text { J. M. Lamet, Ginetta } \\
\text { Mancini }\end{array}$ & Atlántida Films/Cinemar & 1.999 .485 \\
\hline $\begin{array}{l}\text { Simón, contamos } \\
\text { contigo }\end{array}$ & 1971 & Ramón Fernández & $\begin{array}{l}\text { J. J. Alonso Millán, } \\
\text { R. J. Salvia }\end{array}$ & J. J. López Gutiérrez & 1.376 .187 \\
\hline $\begin{array}{l}\text { ¿Vente a Alemania, } \\
\text { Pepe! }\end{array}$ & 1971 & Pedro Lazaga & $\begin{array}{l}\text { V. Coello } \\
\text { V. Escrivá }\end{array}$ & $\begin{array}{l}\text { Aspa P. Cinematográficas/ } \\
\text { Filmayer }\end{array}$ & 2.078 .570 \\
\hline $\begin{array}{l}\text { Los novios de mi } \\
\text { mujer }\end{array}$ & 1972 & Ramón Fernández & $\begin{array}{l}\text { J. J. Alonso Millán, } \\
\text { R. J. Salvia }\end{array}$ & Urfesa P.C. & 1.304 .953 \\
\hline $\begin{array}{l}\text { París bien vale una } \\
\text { moza }\end{array}$ & 1972 & Pedro Lazaga & J. M. Palacio & Estudios Roma & 1.082 .368 \\
\hline $\begin{array}{l}\text { Vente a ligar al } \\
\text { Oeste }\end{array}$ & 1972 & Pedro Lazaga & $\begin{array}{l}\text { V. Coello, } \\
\text { V. Escrivá }\end{array}$ & $\begin{array}{l}\text { Aspa P. Cinematográficas/ } \\
\text { Filmayer }\end{array}$ & 1.233 .433 \\
\hline $\begin{array}{l}\text { ¡No firmes más } \\
\text { letras, cielo! }\end{array}$ & 1972 & Pedro Lazaga & $\begin{array}{l}\text { V. Coello, } \\
\text { V. Escrivá }\end{array}$ & $\begin{array}{l}\text { Aspa P. Cinematográficas/ } \\
\text { Filmayer }\end{array}$ & 1.182 .617 \\
\hline $\begin{array}{l}\text { Guapo heredero } \\
\text { busca esposa }\end{array}$ & 1972 & Luis María Delgado & J. J. Alonso Millán & Diasa P.C. & 1.274 .029 \\
\hline Manolo, la nuit & 1973 & Mariano Ozores & $\begin{array}{l}\text { V. Coello, } \\
\text { M. Ozores } \\
\end{array}$ & $\begin{array}{l}\text { Estudios Roma } \\
\text { Filmayer }\end{array}$ & 1.230 .424 \\
\hline Jenaro el de los 14 & 1973 & Mariano Ozores & $\begin{array}{l}\text { V. Coello, } \\
\text { M. Ozores } \\
\end{array}$ & $\begin{array}{l}\text { Estudios Roma } \\
\text { Filmayer }\end{array}$ & 1.086 .327 \\
\hline $\begin{array}{l}\text { Dormir y ligar: todo } \\
\text { es empezar }\end{array}$ & 1974 & Mariano Ozores & $\begin{array}{l}\text { J. J. Alonso Millán, } \\
\text { M. Ozores, } \\
\text { A. Paso, } \\
\text { J. A. Porto, } \\
\text { R.R. Marchent }\end{array}$ & Lotus Films & 1.075 .099 \\
\hline El reprimido & 1974 & Mariano Ozores & $\begin{array}{l}\text { J. J. Alonso Millán, } \\
\text { M. Ozores }\end{array}$ & $\begin{array}{l}\text { Producciones Cinema- } \\
\text { tográficas D.I.A. }\end{array}$ & 1.078 .244 \\
\hline $\begin{array}{l}\text { Cuando el cuerno } \\
\text { suena }\end{array}$ & 1975 & Luis María Delgado & S. Moncada & José Frade P.C. & 1.236 .123 \\
\hline
\end{tabular}

Fuente: Elaboración propia a partir de datos publicados por el Instituto de la Cinematografía y de las Artes Audiovisuales (ICAA) en la página web del Ministerio de Educación, Cultura y Deporte del Gobierno de España y por la base de datos IMDb (consultadas el 30 de junio de 2015 ). 


\section{EL CINE POPULAR DEL TARDOFRANQUISMO: REPRE- SENTACIONES SOCIALES}

En líneas generales, las manifestaciones más populares del cine español han despertado un interés menor en la historiografía nacional, al menos en comparación con otras. Los análisis sobre los valores estéticos de las producciones más prestigiosas han monopolizado la atención académica, quedando relegadas a un plano residual aquellas vías de abordaje que estudian el discurso cinematográfico como una concreción de la cultura colectiva en permanente diálogo con su entorno (Palacio, 2007).

Esto es así en lo que concierne al período histórico que Tusell (1988, p. 261), entre otros, llama "tardofranquismo". En la parcela cinematográfica se fraguan durante la última década de la dictadura tres grandes alternativas: el cine metafórico, que tiene en las producciones de Elías Querejeta y en películas como El espíritu de la colmena (Víctor Erice, 1973) o La prima Angélica (Carlos Saura, 1974) algunos de sus ejemplos más conocidos; el cine de vocación más comercial, con un arsenal de producciones con taquillajes millonarios y facturadas con una elaboración menor (a menudo rodajes urgentes y sin sonido directo, con escasez de celuloide y propensión a pocas tomas, etcétera); y la "tercera vía", una solución liderada por el productor José Luis Dibildos que intentaba situarse a medio camino entre el elitismo del primero de los grupos señalados y el trazo grueso del segundo.

Seguramente como consecuencia del carácter subsidiario que la historiografía suele conceder a los aspectos sociológicos del hecho fílmico, las películas de mayor éxito comercial durante el tardofranquismo configuran un corpus menos estudiado. Algunos autores lo han catalogado como "cine de subgéneros" (Monterde, 1993; Torreiro, 1995; Seguin, 2002), mientras que otros lo han incorporado a otra especie más general y de cierta tradición histórica como es "la españolada" (Navarrete, 2009).

La carga peyorativa con la que a menudo se emplean esas etiquetas convive, sin embargo, con otras perspectivas analíticas más recientes que completan los vacíos existentes gracias a la toma en consideración de los condicionantes y efectos sociales de ese tipo de obras. En este sentido, destacan en los últimos años la publicación de diversos trabajos que siguen dicho enfoque (Pérez y Huerta, 2013; Faulkner, 2013; Huerta y Pérez, 2012a; Benet, 2012; Labany y Pavlovic, 2013).

En realidad, y con sus respectivos matices, todos esos trabajos parten de convicciones latentes aunque dispersas tiempo atrás. Recio (1992, p. 30), por ejemplo, ya citaba en su trabajo sobre Alfredo Landa unas declaraciones en las que el escritor Francisco Umbral defendía la utilidad del cine popular del tardofranquismo como documento social para el futuro, muy por encima de aquellos filmes que disfrutaban de mayor reconocimiento estético. Y Galán $(1975$, p. 89) fue en los años setenta uno de los primeros en avisar de la contradicción que suponía considerar "cine político" tan solo a aquél que se oponía al poder establecido, pues la carga "política" estaba presente de igual modo en producciones -más abundantes- que defendían el orden impuesto sin necesidad de presentarse como vehículos ideológicos.

Parece fuera de duda que parte de la popularidad de los filmes más comerciales del tardofranquismo reposa sobre la interacción de sus argumentos con un contexto social que llena de sentido tanto las estrategias de producción como los términos de lectura aplicados por el público al que se dirigen. La coyuntura se definió, entre otros muchos y variados factores, por un intento de modernización que tuvo en los famosos Planes de Desarrollo de 1962 y 1969 sus exponentes más emblemáticos. Se trataba, en términos generales, de un intento por parte del Régimen de situarse en la senda europea del progreso por la vía de la economía de consumo, con el automóvil Seat 600 y el crecimiento de la industria turística como dos apuestas de gran influencia simbólica.

Todo ello dio pie a una especie de tensión producida por los cambios, pues a mediados de los ochenta la idea de "cambio" se había convertido ya en algo más relevante que la de "estructura" (Tezanos, 1984, p. 20). En un ambiente general de transformaciones, el intervalo tardofranquista se caracteriza también por el aumento de los trasvases del campo a la ciudad -lo que intensifica la modificación de la fisonomía de las ciudades mediante la expansión urbanística- y por la desigual incorporación de la mujer al mundo laboral. A todo ello habría que sumarle la especial intensidad de la emigración exterior en los sesenta y primeros setenta, el intento de España en 1962 de ingresar en el Mercado Común Europeo -saldado con una negativa-, así como el aumento de la inversión extranjera. Durante la última etapa del franquismo se produjo, en suma, lo que podría calificarse como "la gran transformación" (Juliá, 1999, p. 184), marcada, igualmente, por el crecimiento de unas clases medias a las que el régimen intentó despolitizar.

El cine popular, lejos de permanecer al margen de semejante contexto, se hizo eco de los asuntos más 
candentes de lo que le resultaba actual y los incorporó a las tramas con insistencia. Es más, el tema que sirve de pilar central a los filmes más taquilleros del tardofranquismo es, precisamente, el conflicto entre tradición y modernidad en un entorno marcado por el cambio social.

El modo en el que se desarrolla ese gran asunto asume concreciones variadas. Por ejemplo, la pareja formada por los actores Manolo Escobar y Concha Velasco protagoniza algunos filmes que plantean el choque entre el galán folclórico y tradicional y la joven moderna que asimila la cultura europeizante y yeyé, colisión que se resuelve invariablemente a favor del primero. Títulos como Pero... ien qué país vivimos! (José Luis Sáenz de Heredia, 1967) -que plantea un concurso televisivo en el que rivalizan un cantante de copla y una artista pop, ambos con gran carisma entre dos sectores muy diferenciados de la audiencia-y Relaciones casi públicas (José Luis Sáenz de Heredia, 1968) explotan argumentalmente ese contraste (Ciller y Palacio, 2011).

Por otro lado, el actor Paco Martínez Soria pone cuerpo y voz en la misma época al arquetipo de un patriarca de dotes benefactoras que soluciona los problemas de un grupo -su propia familia u otro tipo de comunidad-amenazado de disolución por culpa de los nuevos tiempos, cuya fuerza disolvente queda neutralizada gracias a la puesta en práctica de sus valores tradicionales. En los casos más significativos - La ciudad no es para mí (Pedro Lazaga, 1966), El turismo es un gran invento (Pedro Lazaga, 1968), Abuelo made in Spain (Pedro Lazaga, 1969)- se plantea la dicotomía con la fórmula entorno rural/entorno urbano (Huerta y Pérez, 2012b).

Y, más allá de nombres propios que interpretan personajes arquetípicos, emerge de forma insistente un discurso sobre una serie de modas que parecen transformadoras de las relaciones sociales -las minifaldas, la lencería, los biquinis y, en general, lo concerniente a una cierta apertura en el terreno sexual, todo ello como parte de un campo más completo en el que emergen otros símbolos de una cultura pop de procedencia extranjera-, lo que suelen terminar con desenlaces ejemplarizantes sobre la necesidad de mantener unas costumbres asociadas a la identidad nacional por la vía de la costumbre.

En ese plano, las estrategias de construcción dramática vinculadas a la representación de hombres y mujeres en el ciclo más exitoso del tardofranquismo ejemplifican buena parte de una de las fases más interesantes de la historia de la cultura popular española y de la sociología del cine nacional. Dicho grupo de obras está liderado por Alfredo Landa, estrella de varios largometrajes que transcienden el puro éxito comercial para construir una de las figuras más reconocibles de entre los iconos que pueblan la memoria colectiva.

\section{EL 'LANDISMO’ TARDOFRANQUISTA: CARACTERÍSTICAS GENERALES}

Un rasgo básico llama la atención antes que cualquier otro en las películas protagonizadas por Alfredo Landa durante el tardofranquismo: todas ellas tienen la forma de comedias ligeras sin aparentes pretensiones y ubican sus argumentos en su entorno inmediato, tanto temporal como espacial. En ese sentido, participan de las características generales sintetizadas por Del Amo en su imprescindible estudio sobre la comedia cinematográfica española (2009), especialmente útil por la enumeración que hace de los rasgos de los personajes de las películas populares del tardofranquismo en relación con su roles sociales, económicos, afectivos, etcétera.

Por otra parte, el 'landismo' es un fenómeno singular que, sin embargo, conviene entender en el marco de una tradición cultural más amplia de la que participan manifestaciones que van desde la novela picaresca hasta la literatura costumbrista, el entremés, la zarzuela, la música folclórica e incluso la canción lírica (Navarrete, 2009, pp. 51-88). De forma complementaria, las películas protagonizadas por Landa durante el período estudiado conviven con expresiones similares que de forma coétanea se dan en otros países, sobre todo en Italia, país que facturó de forma intensiva comedias con toques eróticos de trazo grueso, vehiculadas por actores populares como Lando Buzzanca, Lino Banfi o Mario Carotenuto, entre otros.

En cualquier caso, un primer análisis de los filmes 'landistas' depara constantes interesantes: los relatos, por ejemplo, transcurren en lo que podríamos denominar el "aquí" (territorio español, especialmente Madrid y entornos costeros con atractivos turísticos) y el "ahora" (el presente que los ve nacer), con abundancia de escenarios naturales y conflictos que formaban parte de una sociedad en pleno proceso de cambio, desde luego no en la organización política pero sí en cuanto a los usos y costumbres que estaban vigentes. 
Ahí radica una de las directrices más destacables de las producciones que contaron con Landa como estrella, condición que asumió a finales de los sesenta y tras encadenar un número nada despreciable de papeles como secundario. Indudablemente se dieron unas condiciones de producción idóneas para generar en serie éxitos comerciales que se concentraron en escaso margen de tiempo. La vis cómica del actor era la parte más visible de un trabajo en equipo que funcionó de manera estable a lo largo de los 19 largometrajes con más de un millón de espectadores que Alfredo Landa protagonizó entre 1969 y 1975. Llama la atención que dichos filmes estén dirigidos por solo 7 directores -Mariano Ozores (5), Ramón Fernández (4), Pedro Lazaga (4), Luis María Delgado (2), Fernando Merino (2), José Luis Sáenz de Heredia (1) y Manuel Summers (1)-. Además, pocos guionistas firmaron estos trabajos, repitiendo así tanto con el intérprete como con algunos realizadores -Juan José Alonso Millán (8), Vicente Coello (6), Vicente Escrivá (4), Alfonso Paso (3), Juan Miguel Lamet (2), y Rafael J. Salvia (2) fueron los que firmaron o co-firmaron al menos más de un guión-. De hecho, la coincidencia de profesionales en torno a lo que se convirtió en un filón es extensible a las compañías productoras -Filmayer (7), Aspa Producciones Cinematográficas (4), Estudios Roma (3), Atlántida Films (2) y José Frade Producciones Cinematográficas (2) levantaron más de un proyecto como mínimo-.

A partir de semejante concentración de equipos creativos y de agentes de producción, es lógico pensar en la aplicación de rutinas que favorecían la agilidad de los procesos, así como la reiteración de fórmulas expresivas, genéricas y temáticas que se demostraron muy funcionales. De hecho, parte del éxito del 'landismo' se debió a la habilidad que tuvo esa maquinaria de autoría colectiva a la hora de sintetizar los anhelos y temores del público masivo, por supuesto también -o quizás, principalmente- en lo tocante a las relaciones afectivas y/o eróticas, un vector clave de esa colisión entre lo viejo y lo nuevo del que tanta cuenta dio el cine popular de segunda mitad de los sesenta y primeros setenta.

De hecho, los títulos de los filmes constituyen una declaración de principios al respecto: el adulterio - ¿Por qué te engaña tu marido?, Los novios de mi mujer, Cuando el cuerno suena-, la sugerencia del encuentro sexual -Cuatro noches de boda, París bien vale una moza, Dormir y ligar: todo es empezar-, la posibilidad de la prostitución masculina -Los días de Cabirio, Manolo, la nuit-y la conflictividad del deseo
-El reprimido- son temas enunciados como reclamos desde las carteleras y aclaran una de las constantes más significativas del 'landismo'.

En general, y tras largas décadas de puritanismo, la cultura popular empezaba a aprovechar una relajación sobre lo que era admisible representar. A pesar de todo, los mecanismos censores funcionaban a pleno rendimiento, ahora bajo el nombre de Junta de Censura y Apreciación de Películas -desde el decreto de 14 de enero de 1965- y bajo el paraguas de la Ley de Prensa e Imprenta de 18 de marzo de 1966, cuyo polémico artículo 2, a pesar de propugnar la libertad de expresión, establecía tales limitaciones que dejaba sin efecto cualquier posibilidad de cambio.

Las producciones populares tardofranquistas debían someterse a la lupa de la censura, como el resto, aunque el trato recibido por el entramado censor fue bien distinto, pues los mecanismos vigilantes estaban más preocupados del cine disidente que de este tipo de películas, en torno a las cuales analizaban sobre todo la cantidad de piel que mostraban y ciertos chistes o comentarios. En cuanto a ambos extremos, los responsables eran perfectamente conscientes de en qué campo jugaban y cuáles eran las líneas que no debían traspasar. En general, de hecho, se dio una relación tensa pero no demasiado problemática, pues los guionistas y directores solían acatar los límites y los censores eran conscientes de ello. Así se deduce, por ejemplo, de algunas reflexiones de Mariano Ozores realizador de hasta cinco largometrajes 'landistas'-, para quien la censura "no fue demasiado perjudicial" (Ozores, 2002, p. 148).

En cualquier caso, resulta elocuente, como veremos de inmediato, el grado de insistencia con el que las obras estudiadas aplican determinadas estrategias de construcción dramática y puesta en escena para vertebrar un discurso homogéneo sobre cómo se canalizan los impulsos y deseos, pues del desenlace de las tramas se deriva una intencionalidad didáctica por pura insistencia. Además, lo más significativo es el modo en el que se plantea la vivencia de lo romántico con tajantes diferencias de género que constituyen un interesante catálogo de modelos de conducta según se pertenezca al sexo masculino o femenino.

\section{LA FIGURA MASCULINA COMO AGENTE DOMINANTE}

"Viajante de comercio, ya ha pasado los treinta, tozudo cuando hace falta, impetuoso, católico, aficionado al fútbol y bajito. Es decir, es un español medio... normal". La descripción, enunciada por la voz over 
de un narrador extradiegético, corresponde a Lucas Trigo, el individuo interpretado por Alfredo Landa en El reprimido (Mariano Ozores, 1974). El retrato constituye, sin duda, un caso paradigmático de la visión que sobre el hombre transmite el 'landismo' a partir de sus protagonistas, pues la masculinidad tiende a ligarse al origen patriótico y a una serie de creencias, rasgos y hábitos tan delimitados como tradicionales.

De hecho, y aunque el filme admite matices en su interpretación, el arquetipo del macho ibérico encuentra en Landa su plasmación más conocida. No es la única, por supuesto, pues durante la última fase del franquismo cohabitó su estrellato con el del galán hispánico encarnado por Manolo Escobar. Este, sin embargo, puso cuerpo a una masculinidad racial que funcionaba por proyección, alguien elevado -son frecuentes los contrapicados y otros recursos formales y narrativos que tenían por objeto el ensalzamiento de su figura- y heroico a quien el espectador implícito aspiraba a parecerse. El 'landismo', por el contrario, operaba mediante la identificación, pues se apelaba al sueño de que cualquier español podía gozar, por el simple hecho de serlo, de las oportunidades sexuales que traían los nuevos tiempos.

Por otra parte, la mayor parte de los argumentos atribuyen la iniciativa de las acciones más relevantes a los varones y someten a las mujeres a un rol subsidiario -feliz, eso sí- respecto a ellos. El protagonismo es claramente masculino, tanto en lo relativo a la construcción del punto de vista desde el que se cuentan las historias como al peso de los conflictos que se ponen en liza. Además, la caracterización del varón en el relato es bastante más completa e incluye su faceta profesional, identificada con claridad en todos los casos. Al respecto, cabe añadir que el prototipo 'landista' responde usualmente al perfil de trabajador no cualificado -con alguna excepción como la de ¿Por qué te engaña tu marido?, en la que Landa encarna a un médico-, asalariado del sector servicios -empleado de banca, agente turístico, botones, camarero, agente comercial, etcétera- o encargado de tareas agrícolas y ganaderas. En algunos casos concretos, esta dimensión profesional tiene especial incidencia en las tramas, sobre todo cuando necesita recurrir al pluriempleo para ganarse la vida, lo que sucede en los filmes i Vente a Alemania, Pepe!, Jenaro el de los 14 y Dormir y ligar: todo es empezar.

No obstante, los roles vinculados al trabajo tienden a supeditarse a la esfera de lo afectivo, lo romántico y lo sexual, núcleo central de las peripecias que articulan los relatos. Dichas dimensiones acaban, como veremos de inmediato, poniéndose sistemáticamente al servicio de las estructuras tradicionales de convivencia y de la perpetuación del papel que en su seno corresponde a hombres y a mujeres.

\section{El amor romántico como algo ajeno al varón}

El amor no es, precisamente, uno de los sentimientos predilectos de los protagonistas encarnados por Landa. Su atracción por las mujeres se circunscribe casi exclusivamente a la satisfacción de unos instintos sexuales que afloran de forma incontrolable.

El enamoramiento o la necesidad emocional por completarse junto a otro ser humano -las distintas acepciones de la RAE apuntan en esa dirección- se da muy excepcionalmente. El hombre parece no estar concebido para la vivencia de lo amoroso, algo que incluso tiende a quedarse fuera de toda verbalización a jóvenes cortejadas, novias formales, esposas o amantes.

Solo en los contados casos en los que el tono melodramático se sitúa en un nivel parejo al cómico emerge la excepción. Así ocurre en Cateto a babor (Ramón Fernández, 1970), filme en el que un sencillo hombre de pueblo se enamora de la hija ciega de su sargento durante el servicio militar ${ }^{2}$. En este caso la atracción emocional anula el instinto erótico para formular una analogía ejemplarizante: la joven se opera, recupera la visión y comprueba con sus propios ojos que su amado es tal y como se lo imaginaba... mientras que este termina descubriendo (en cierto modo, también recupera la "visión") la pureza de los valores que la Marina, como institución, defiende y practica.

\section{La sexualidad y su dimensión racial: el macho ibérico}

Cateto a babor es una rareza en la filmografía 'landista', atravesada de principio a fin por una sexualidad instintiva como eje articulador. De ello es paradigma, sin duda, Manolo, la nuit (Mariano Ozores, 1973), en la que un narrador describe en over al protagonista como alguien que levanta admiración entre las visitantes extranjeras por tratarse de un "colosal producto que salió del cruce de dos pueblos fuertes, rudos y primitivos: los celtas y los íberos".

Ese "racial celtíbero español", de nombre Manolo, es un agente turístico cuyos favores sexuales se disputan las esbeltas jóvenes llegadas desde el norte. Y él, a pesar de sentirse atosigado, las atiende por las noches en sus habitaciones de hotel, sin que sea un obstáculo el hecho de estar felizmente casado desde hace tiempo. Cuando su esposa se entera de lo que sucede 
amenaza con serle infiel, lo que desata una obsesión celosa. Finalmente, la estabilidad del hogar queda asegurada en el desenlace con el feliz embarazo de la mujer, que pasa a sentirse plenamente realizada con la noticia y con el cambio de comportamiento que le promete su marido.

Manolo, la nuit parece abrir la puerta a una visión prostituida del varón, algo que se concretará de forma mucho más explícita en Los días de Cabirio, en la que Landa pone cuerpo y voz a un tipo que se dedica al oficio de "palanquero" para ganar un dinero fácil. Desde luego sus protagonistas no son los únicos ejemplares de "macho ibérico" encarnados por Landa, imagen viva del arquetípico personaje, que reitera en un título tan exitoso como No desearás al vecino del quinto (Ramón Fernández, 1970) determinados perfiles físicos y psicológicos: a pesar de que su complexión no parece en absoluto atlética, se trata de un amante impetuoso y de voraz apetito carnal. El rasgo se atribuye a una predisposición racial, pues se explica como una cualidad española. La caracterización se completa con la probada fertilidad del arquetipo 'landista', ya que sus prácticas -aun motivadas por un hedonismo superfluosuelen deparar frutos en el terreno de la natalidad.

Los relatos celebran así el mito del español como semental, conclusión que se hace especialmente patente en Cuando el cuerno suena (Luis María Delgado, 1974), en la que Pepe -los nombres, tan comunes, evidencian la búsqueda de la identificación de lo que se consideraba el espectador medio- descubre que no es, como pensaba todo el mundo, un hombre "de gametos perezosos" -pues hasta entonces parecía incapaz de dejar embarazada a su mujer-cuando mantiene relaciones adúlteras con tres jóvenes que se quedan encinta.

En cuanto a capacidad procreadora destaca también el protagonista de Simón, contamos contigo, quien aunque ayudado por una pócima mágica que le lega su padre y que pasa de generación en generación para asegurar el patriarcado familiar-acaba teniendo siete hijos... hasta que le llega la muerte. Tanto el Simón de este largometraje como el Pepe de Cuando el cuerno suena dan cuenta, además, de otro de los perfiles de los personajes de Landa, tipos que a pesar de su apariencia más bien mediocre desatan una atracción irresistible entre las féminas.

El símbolo del hombre que sin ser guapo tiene un atractivo arrollador y que, además, asegura la procreación, se asienta hasta tal punto que llega a admitir su variación irónica, fundada sobre personajes inapetentes. Las razones son variadas. Saturnino, por ejemplo, no puede en Dormir y ligar: todo es empezar (Mariano Ozores, 1974) "cumplir" sus deberes conyugales porque los vecinos de su pueblo lo tienen sobrecargado de trabajo. Algo similar le sucede a Pedro en No desearás la mujer del vecino (Fernando Merino, 1971), si bien este sufre una adicción laboral en la cosmopolita sociedad de consumo, cuestión abordada con frecuencia -y ciertas dosis de desconfianza- por el resto de la cinematografía popular del tardofranquismo. A los dos casos hay que sumarles el de Lucas en El reprimido, película en la que las restricciones carnales del varón llevan a un cuestionamiento de su virilidad, motivo por el que su pareja llega a lamentarse con la frase "qué mala suerte, he ido a enamorarme de un español único".

En líneas generales, nos encontramos con sutiles variantes sobre el mismo punto de vista: la mujer es percibida como un objeto de deseo que o bien resulta intercambiable o bien es agente provocador de temores en quien es víctima de una represión. Solo así se entienden alusiones tan explícitas como las de Fidel Frutos en Guapo heredero busca esposa, en la que llega a confesar "a mí las mozas me dan miedo... si hubiera sido con una oveja, aún...".

Con todo, lo más relevante es que las tramas terminan reconduciendo los problemas a lo que consideran solución propia de un orden natural. Todos los protagonistas superan sus traumas y dificultades, mientras las posibles veleidades -pues buscan solución a sus problemas con otras compañeras de alcoba- dejan paso en las resoluciones a una misma idea: la restitución de la estabilidad familiar gracias a la recuperación de las dotes sexuales, siempre en el seno del matrimonio y a menudo rematada con la guinda de un embarazo.

\section{Las relaciones familiares: el matrimonio como medio para la sexualidad, el adulterio naturalizado y la pa- ternidad como epílogo}

El sexo no es solo fuente de conflicto y motor narrativo de las comedias lideradas por Alfredo Landa sino también fuerza reguladora de los afectos que se le atribuyen al varón. Si la opción romántica queda descartada -al menos en un sentido convencional- la vivencia de lo familiar constituye otro obstáculo para el goce pleno de los placeres eróticos.

De ese modo, los filmes plantean desde la perspectiva masculina una idea del matrimonio como mal necesario, medio inevitable para dar satisfacción a 
los deseos propios. ¿Por qué te engaña tu marido? es la película más significativa en ese sentido, pues su protagonista (Eduardo) fantasea con la vida conyugal que tendría al lado de cuatro mujeres distintas, cuyas muertes van sucediéndose unas tras otras después de que el marido lo desee con toda su alma. El final de esta exploración psicoanalítica de los miedos de un hombre común es también ilustrativa: conoce en el cementerio a una viuda que está enterrando a su esposo y que se le insinúa de inmediato. Eduardo huye, pero el narrador aparece entonces en la sala de montaje reclamando un final feliz "para las espectadoras", por lo que el epílogo consiste en un beso apasionado que parece anunciar una nueva boda.

El casamiento es, pues, el camino obligatorio para el desahogo sexual, lo que comporta sufrimientos con las esposas y/o con las suegras, que en ocasiones actúan como acompañantes dañinas. La voracidad consumista de la primera y el empeño por minar la moral de la segunda detonan los conflictos más importantes de iNo firmes más letras, cielo! Y Cuatro noches de boda se suma a la mitología del lecho nupcial como destino obligado -por puro arbitrio moral- si se pretende la satisfacción de lo que se presenta como necesidad biológica del varón.

Solo desde esa premisa puede entenderse el modo en el que se aborda el adulterio y que evidencia otra de las obsesiones sentimentales del período. En líneas generales, el individuo tipo interpretado por Landa es infiel por naturaleza. Su cualidad ya descrita de sujeto voraz dada la doble condición de hombre y de español tiene aquí su continuidad con el hábito del engaño, practicado o probable por poderosa tentación en ¿Por qué te engaña tu marido?, El alma se serena, No desearás al vecino del quinto, Los días de Cabirio, No desearás la mujer del vecino, iVente a Alemania, Pepe!, Simón, contamos contigo, Los novios de mi mujer, Vente a ligar al Oeste, Manolo, la nuit, Jenaro el de los 14, Dormir y ligar: todo es empezar y Cuando el cuerno suena, un número muy alto de filmes con títulos, por otro lado, tan significativos y didácticos que contribuyen a generar la imagen normalizada del español como sujeto predispuesto a no relacionarse con una sola mujer.

La concepción sexualizada de la existencia se superpone y limita otras esferas vitales. Los personajes interpretados por Landa tienen un recorrido familiar más bien escaso, especialmente en lo relativo a su papel de padres. A ese respecto su responsabilidad es engendradora y garante de la viabilidad económica del hogar que funda. Las obligaciones educadoras o afectivas son prácticamente nulas, completando así el establecimiento de una misión asociada a los instintos sexuales -para perpetuación de la especie- y a lo laboral, dos esferas que entran a menudo en contacto con la realización de las féminas, cuya función es tan distinta como complementaria.

\section{LA FIGURA FEMENINA SUBSIDIARIA Y EL ATRACTIVO DESPERSONALIZADO}

El ciclo 'landista' está marcado por el protagonismo casi absoluto de los personajes masculinos, característica por otro lado común en el cine popular del tardofranquismo. Varios de los intérpretes más importantes del período son varones y encarnan diversos arquetipos que, con sus correspondientes aristas, aseguran la existencia de lo que podría considerarse como un mundo patriarcal.

Durante el tardofranquismo la gran excepción la representa Lina Morgan, ejemplo de una comicidad que, sin embargo, no pierde matiz misógino dado su protagonismo en títulos tan elocuentes como Soltera y madre en la vida (Javier Aguirre, 1969), La tonta del bote (Juan de Orduña, 1970) o La descarriada (Mariano Ozores, 1973). No es ninguna excepción, pues, que en la filmografía liderada por Landa las mujeres desempeñen una función de servicio al lucimiento del actor. La nómina de profesionales que le acompañan en los repartos es de lo más variada e incluye nombres como los de Esperanza Roy, Concha Velasco, Ingrid Garbo, Patty Shepard, Ira von Fürstenberg, Mirta Miller, Sylva Loscina o Helga Liné. Todas -a excepción de Lina Morgan o Tina Sáinz en los argumentos que cuentan con algún añadido melodramático- actrices de gran atractivo físico, explotado con desenfado por las estrategias de puesta en escena.

En líneas generales, ellas forman parte de los conflictos del varón hasta convertirse en simples complementos. Las compañeras de reparto de Alfredo Landa tienden a meterse en la piel de mujeres cuya esfera profesional no existe más allá del cuidado del hogar y la atención a sus cónyuges o novios. Resulta llamativo que las excepciones en las que se refiere algún tipo de aspiración o práctica relacionada con el trabajo fuera de lo doméstico consistan en una aspirante a monja -Simón, contamos contigo-, una timadora -París bien vale una moza-, una exmodelo -iNo firmes más letras, cielo!-, una excabaretera -Cuando el cuerno suena- y dos prostitutas -Guapo heredero busca esposa y Jenaro el de los 14-. 
A todas ellas les aguarda, por lo general, la redención en forma de conquista de la estabilidad en un hogar tradicional. Para llegar a ello, emplean trucos o señuelos con los que logran la continuidad de las reglas de convivencia, la anulación de las tentaciones que asedian a sus compañeros y el mantenimiento de los roles afectivos existentes antes de la llegada de las modas que parecen estar transformando el ambiente social.

\section{Romanticismo y feminidad}

Tampoco son las obras del ciclo landista un ejemplo de romanticismo exacerbado en lo concerniente a los universos femeninos. Estas comedias, de hecho, tienden al costumbrismo y a la picaresca más que a una visión idílica del romance. Los recursos que las forjan son más propios de un humor grueso en la dimensión sentimental que fruto de la idealización que suponga para ellas la culminación de una utopía amorosa.

Lo que abundan, en realidad, son los afectos definidos por otro tipo de objetivos. Las mujeres que rodean al protagonista encarnado por Landa o bien desean disfrutar de su capacidad sexual -cuando son turistas y/o tienen una moral dudosa- o bien buscan en él un instrumento necesario para crear un hogar.

Las emociones se asocian con frecuencia a lo estrictamente material. En ocasiones el reproche por "no sentirse queridas" tiene que ver con otro concepto habitual en el cine del período como es "no sentirse atendidas". Lo habitual es que la promesa de matrimonio, su culminación y/o un embarazo solucione los conflictos de las féminas, algo para lo que deben adoptar una actitud provocadora que movilice instintivamente al varón.

\section{El ardid sexual y la cosificación del cuerpo femenino}

La visión romántica de la existencia por parte de la mujer tiene una incidencia menor en comparación con la faceta sexual. Si el hombre es epicentro de los relatos y si estos se nutren de conflictos principalmente vinculados a sus impulsos y deseos, ellas se acomodan a las reglas del juego para poner en marcha sus estrategias. Conscientes de que la sociedad de consumo, el turismo y el desarrollo económico traen consigo un entorno lleno de tentaciones para sus pretendientes, novios o maridos, aprovechan la oportunidad para usar todo tipo de ardides eróticos en la consecución de sus objetivos.

La mirada que proyectan los largometrajes a este respecto desprende un tono didáctico con connotaciones patrióticas, tal y como describíamos en la sem- blanza del macho ibérico. Aquí la clave principal tiene que ver con el concepto de "decencia", asociado a la mujer española. Esta puede coquetear, insinuarse y alterar desde la picardía a sus compañeros, pero los fines carnales de estos no se satisfacen si no observan los códigos tradicionales. Las extranjeras -o las pocas nacionales que se han dejado llevar por la influencia foránea o que ejercen la prostitución- pueden, sin embargo, ir más allá sin demasiados remilgos, lo cual las inhabilita para gozar de un futuro emocional o familiar junto al protagonista.

Manolo, la nuit, No desearás al vecino del quinto, El alma se serena -en la que un amigo del protagonista pretende montar una orgía con dos mujeres de raza negra calificadas textualmente de "salvajes"-, Los días de Cabirio, París bien vale una moza, Vente a ligar al Oeste o Cuando el cuerno suena dejan múltiples ejemplos de lo expuesto. Y es que el interés por el placer carnal que asegura el macho español, su potencia engendradora u otras aspiraciones materiales -en Jenaro el de los 14 el atractivo lo ponen unos millones de pesetas que llueven del cielo gracias a una quiniela- son algunas de las motivaciones más destacables de las féminas.

Los prototipos femeninos coinciden sin embargo en el trato que reciben por un dispositivo estético recurrente en el cine popular tardofranquista: la inercia a reducir sus identidades a su corporeidad, exhibida con tácticas de planificación que hacen de ellas objetos de deseo para la mirada varonil. Además de que las minifaldas, las medias, la lencería o los zapatos de tacón forman el vestuario más habitual, la cámara se ubica habitualmente en emplazamientos tan poco justificados narrativamente como ventajistas para "disfrute" de la visión tanto de los personajes masculinos como del espectador objetivo al que se dirigen.

La sinécdoque se erige en figura retórica habitual. Muchos encuadres se articulan con la presencia de un muslo femenino mientras el resto del cuerpo queda fuera de campo, definiendo así la identidad con una parte concreta de la anatomía. Al fondo o en una esquina del cuadro queda el hombre que mira con evidente gesto de excitación, siendo así una prolongación diegética de quien se encuentra al otro lado de la pantalla. Valga como ejemplo -pues son incontablesel pasaje de No desearás la mujer del vecino en el que, además de lo dicho sobre la composición, el juego del montaje convencional en plano/contraplano obvia la perspectiva de la joven que intenta seducir con una liga a su desganado marido. 
Esposa y madre: la mujer al servicio de la estabilidad familiar

Las compañeras de viaje en las películas encabezadas por Alfredo Landa se caracterizan ante todo por su vocación de esposas y madres, garantes de la unión familiar y de la permanencia de la tradición. Si en líneas anteriores se daba cuenta del matrimonio como un medio insoslayable para que ellos dieran rienda suelta a sus impulsos -“mucha publicidad, mucho escándalo, mucho jaleo... pero para estar a solas con una mujer nos tenemos que casar", se queja Manuel en El alma se serena- encontramos aquí el complemento en la dirección contraria: la consagración sacramental de la vida en pareja es el objetivo de ellas, que explotan sus encantos físicos para lograr dicho fin.

Matrimonio, sexo y procreación guían su conducta. Si en filmes como No desearás la mujer del vecino se percibe una insatisfacción sexual por parte de dos señoras casadas como consecuencia de las adicciones laborales de sus maridos es porque, sencillamente, todavía no son madres. En feliz embarazo concluye también Manolo la nuit, otro caso de un relato que parte de un tono cómico y descarado en la exploración de la libido de sus personajes para aterrizar en una conclusión conservadora en cuanto al mantenimiento de los roles familiares institucionalizados.

Precisamente en esas dos producciones asoma la distinta concepción que se tiene del adulterio en función del género de sus practicantes. Los relatos presentan una inercia en este sentido al equiparar las infidelidades reales de ellos con las simuladas por sus compañeras. Para las novias y esposas se trata de un juego para provocar celos y conseguir la vuelta al orden -o la ocasional recuperación del brío erótico- de sus parejas, cuyos devaneos provocan tantos enojos como perdones dotados de generosa comprensión, como si dieran por bueno que el engaño de ellos obedece a una inclinación natural. Lo interesante es que, a la hora de resolver las tramas, los desenlaces compensan en cierta manera el adulterio consumado de los varones con el ficticio de las mujeres, colocando así ambas acciones en idéntico nivel moral.

Sobre ese mecanismo se construye, por ejemplo, Los novios de mi mujer, en la que un vendedor de automóviles es cazado por su esposa en compañía de una amiga de la infancia. Esta, por cierto, apela al contexto sociopolítico de la época para justificar su conducta: "estamos en Europa, querida", se justifica en un momento dado la sensual y casquivana seductora. $\mathrm{O}$, dicho de otra forma, la influencia foránea es una amenaza para la tradición española también en este terreno.

\section{CONCLUSIONES}

Tras todo lo expuesto consideramos demostrado que los filmes protagonizados por Alfredo Landa durante el período 1969-1975 configuran un grupo homogéneo dentro de la cinematografía popular del tardofranquismo. La reiteración de constantes en la construcción dramática permite hablar de 'landismo', una corriente específica dentro del cine español más taquillero del período, durante el cual se dieron otros 'ciclos' que -como los liderados por Paco Martínez Soria, Manolo Escobar o Lina Morgan- también tenían a alguna estrella nacional como principal reclamo. Todos ellos, por cierto, están formados por películas que son hoy documentos de gran interés al testimoniar una mentalidad concreta dentro de una circunstancia histórica definida por el cambio.

En concreto, los relatos 'landistas' dialogan vivamente con el contexto en el que surgen. Lo hacen desde presupuestos cómicos y tratamientos costumbristas cohesionados por una vertiente temática: el conflicto entre tradición y modernidad. Así, en líneas generales se da cuenta de una sociedad en plena transformación, con abundancia de asuntos que estaban durante el tardofranquismo a la orden del día: la incorporación de las clases medias a una sociedad de consumo, los problemas derivados de los movimientos migratorios y el crecimiento del turismo son algunos de los más importantes. Sin embargo, uno de las cuestiones más ilustrativas en cuanto a la relación cine-sociedad tiene que ver con la representación de la identidad masculina y femenina.

El grupo de textos analizados destaca por lo que algunos estudios sobre influencia mediática televisiva consideran como "sobrerrepresentación masculina" frente a la "subrepresentación femenina" (Radl, Gómez y García, 2001, p. 321), conceptos que bien pueden aplicarse al ciclo protagonizado por Landa en el intervalo 1969-1975. A la preeminencia en el protagonismo masculino, así como al dominio de su punto de vista en la enunciación de los hechos que jalonan las tramas, hay que sumarles los aspectos -explícitos y denotados- sobre las cualidades que tienen hombres y mujeres en los relatos, vinculados a una muy distinta vivencia de lo sexual y a unos roles familiares tan distintos como complementarios en una visión tradicional que garantiza la estabilidad, tal y como se establece sin duda en la mayor parte de los desenlaces.

La relevancia de la forma en que se difunden los códigos de conducta de los personajes femeninos y masculinos se torna patente cuando quedan demostradas 
visiones estereotipadas como las descritas a lo largo de nuestro trabajo y que no siempre respondían a la realidad histórica. Durante los años del desarrollismo los cambios en la calidad de vida se vieron acompañados de transformaciones que también se dieron en el terreno de los comportamientos, lo cual produjo una relajación de la moral que inquietaba a los sectores más inmovilistas del franquismo. Dichos cambios afectaron en gran medida al papel que desempeñaba la mujer, cuya incorporación a la formación universitaria y al mercado laboral cada vez fue mayor. Por si fuera poco, descendió la nupcialidad, retrocedió la edad con la que contraían matrimonio e incluso se dio un progresivo éxito de la píldora anticonceptiva (Riquer, 2010, p. 661). Todo ello chocaba con la abundancia de protagonistas femeninas que en las películas 'landistas' carecían de profesión conocida o que se ganaban la vida, en los casos excepcionales, mediante la explotación de su cuerpo. Y, por supuesto, contrastaba con el destino que los filmes les reservaban como esposas y futuras cuidadoras de sus maridos, a los que disculpaban todos sus deslices.

Las películas analizadas participaban así de un doble proceso: por un lado, coqueteaban con la exhibición de unos aires modernos mediante la afloración en pantalla de cuerpos femeninos resaltados gracias a prendas de lencería, biquinis, minifaldas y otros fetiches que formaban parte de las modas del momento. Por otro, sin embargo, respondían a una mentalidad que se oponía al cambio estructural de roles, en sintonía por tanto con la preocupación franquista por mantener como inmutables algunos valores afectivos, familiares y de género.

De este modo, Alfredo Landa, estrella generadora de grandes dosis de identificación, sirvió en cierto modo durante su taquillera trayectoria tardofranquista como vehículo articulador de una representación reiterada del papel que correspondía a hombres y mujeres. La función que corresponde a ambos en cuestiones como el romance, la sexualidad, la vida en pareja, el matrimonio, el adulterio y la paternidad -entre otros- sigue siendo hoy muy ilustrativa desde una perspectiva sociológica, especialmente cuando los códigos de conducta se establecen como referentes o pretenden la empatía. Una conclusión sin duda relevante desde el punto de vista social, ya que si entendemos que el cine es "la gran potencia educadora de nuestro tiempo" (Marías, 2006, p. 211) -y desde luego lo fue durante el siglo XX-, su papel es muy influyente a la hora de generar una visión sobre la realidad, incluso en el caso de aquellos filmes que, como las comedias populares de los primeros años setenta, se disfrazan de pasatiempos sin vocación de trascendencia. Por el contrario, esa apariencia de superficialidad servía para reforzar conceptos como el de la "buena mujer de su casa", un ideal femenino sin duda generalizado por aquel entonces (Arenal, 1974, p. 198).

El análisis de un fenómeno cultural tan relevante $-\mathrm{y}$ escasamente estudiado de forma sistemática- como el 'landismo' tardofranquista contribuye finalmente a un conocimiento histórico con resonancias sobre el presente y en el que la ficción acaba siendo un útil instrumento para explicar los modelos sociales. Nos alineamos, en definitiva, con buena parte de las posiciones historiográficas que defienden que los textos cinematográficos -incluso los de ficción- son herramientas audiovisuales muy útiles para la comprensión de las sociedades audiovisuales (Montero y Paz, 2013).

\section{AGRADECIMIENTOS}

Este artículo ha sido elaborado en el marco del proyecto de investigación "Ideología, valores y creencias en el 'cine de barrio' del tardofranquismo (19661975)", (referencia I+D+i, HAR2009-08187), financiado por el Ministerio de Ciencia e Innovación de España.

\section{NOTAS}

1 La obra original de Kracauer se publicó en 1947.

2 Su carácter excepcional se debe en parte al hecho de ser una nueva versión de la exitosa Recluta con niño (Pedro Luis Ramírez, 1956). 


\section{BIBLIOGRAFÍA}

Arenal, C. (1974). La emancipación de la mujer en España. Madrid: Jucar.

Casetti, F. (2000). Teorías del cine. Madrid: Cátedra.

Ciller, C. y Palacio, M. (2011). Sáenz de Heredia y la Transición (1969-1975). En: Castro de Paz, J. L. y Nieto, J. (coords.). El destino se disculpa. El cine de José Luis Sáenz de Heredia. Valencia: Ediciones de la Filmoteca, pp. 251-262.

Benet, V. (2012). El cine español. Una historia cultural. Barcelona: Paidós.

De Riquer, B. (2010). La dictadura de Franco. Barcelona: Crítica.

Del Amo, Á. (2009). La comedia cinematográfica española. Madrid: Alianza Editorial.

Faulkner, S. (2013). A History of Spanish Film. Cinema and Society 1910-2010. New York: Bloomsbury.

Ferro, M. (1977). Cinéma et Histoire. Paris: Gallimard.

Galán, D. (1975). El cine 'político' español. En: VV.AA. Siete trabajos de base sobre el cine español. Valencia: Fernando Tores, pp. 87-107.

Gunning, T. (2007). Moving away from the index: Cinema and the impression of reality. Differences, 18, 1, pp. 29-52.

Huerta, M. A. y Pérez, E. (eds.) (2012a). El "cine de barrio" tardofranquista. Reflejo de una sociedad. Madrid: Biblioteca Nueva.
Huerta, M. A. y Pérez, E. (2012b). La creación de discurso ideológico en el cine popular del tardofranquismo (19661975): el 'ciclo Paco Martínez Soria'. Comunicación y Sociedad, XXV, 1, pp. 289-311.

Juliá, S. (1999). Un siglo de España. Políticia y sociedad. Madrid: Marcial Pons.

Kracauer, S. (1995). De Caligari a Hitler: una historia psicológica del cine alemán. Barcelona: Paidós.

Labanyi, J. y Pavlovic, T. (eds.) (2013). A Companion to Spanish Cinema. Chichester: Wiley-Blackwell.

Marías, J. (2006). La educación sentimental. Madrid: Alianza Editorial.

Monterde, J. E. (1993). Veinte años de cine español. Un cine bajo la paradoja. Barcelona: Paidós.

Montero, J. y Paz, M.a A. (2013). Historia audiovisual para una sociedad audiovisual. Historia crítica, 49, pp. 159-183.

Navarrete, J. L. (2009). Historia de un género cinematográfico: la españolada. Madrid: Quiasmo.

Ordóñez, M. (2008). Alfredo el Grande: vida de un cómico. Madrid: Aguilar.

Ozores, M. (2002). Respetable público: cómo hice casi cien películas. Barcelona: Planeta.

Palacio, M. (2007). Estudios culturales y cine en España. Comunicar, 29, pp. 69-73.
Pérez, E. y Huerta, M. A. (2013). La paradoja tardofranquista: aporías del celuloide en la última década predemocrática. Journal of Spanish Cultural Studies, 14, 3, pp. 275-290.

Prendergast, C. (1986). Cinema Sociology: Cultivating the Sociological Imagination through Popular Film. Teaching Sociology, 14, pp. 243-248.

Radl, R., Gómez, B. y García, J. (2001). Influencia mediática televisiva, dinámica familiar y roles de género. Algunos datos empíricos sobre la situación de la adolescencia. En: Radl, R. (ed.). Cuestiones actuales de sociología del género. Madrid: CIS, pp. 297-319.

Recio, J. M. (1992). Alfredo Landa. Barcelona: CILEH.

Rosenstone, R. A. (2006): History on Film/ Film on History. Harlow: Pearson.

Seguin, J-C. (2002). Historia del cine español. Madrid: Acento.

Sorlin, P. (1977). Sociologie du Cinéma. Paris: Aubier-Montaigne.

Tezanos, J. F. (1984). Cambio social y modernización en la España actual. Revista Española de Investigaciones Sociológicas, 28, pp. 19-61.

Torreiro, C. (1995). Del tardofranquismo a la democracia (1969-1982). En: VV.AA. Historia del cine español. Madrid: Cátedra, pp. 341-398.

Tusell, J. (1988). La dictadura de Franco. Madrid: Alianza. 